Article

\title{
Investigation of Ionospheric Response to June 2009 Sarychev Peak Volcano Eruption
}

\author{
Nikolay Shestakov $1,2, *\left(\mathbb{D}\right.$, Alexander Orlyakovskiy ${ }^{1}$, Natalia Perevalova ${ }^{3}$, Nikolay Titkov ${ }^{4}$, Danila Chebrov ${ }^{4}$, \\ Mako Ohzono ${ }^{5,6}$ and Hiroaki Takahashi ${ }^{5}$
}

1 Department of Mining and Oil-Gas, Polytechnical Institute, Far Eastern Federal University, 690922 Vladivostok, Russia; orliakovskii.av@dvfu.ru

2 Institute for Applied Mathematics, Far Eastern Branch of Russian Academy of Sciences, 690091 Vladivostok, Russia

3 Institute of Solar-Terrestrial Physics, Siberian Branch of Russian Academy of Sciences, 664033 Irkutsk, Russia; pereval@iszf.irk.ru

4 Kamchatka Branch of Geophysical Survey of Russian Academy of Sciences, 683023 Petropavlovsk-Kamchatsky, Russia; nik@emsd.ru (N.T.); danila@emsd.ru (D.C.)

5 Institute of Seismology and Volcanology, Hokkaido University, Sapporo 0600810, Japan; m.ohzono@sci.hokudai.ac.jp (M.O.); hiroaki@sci.hokudai.ac.jp (H.T.)

6 Earthquake Research Institute, University of Tokyo, Tokyo 1130032, Japan

* Correspondence: shestakov.nv@dvfu.ru; Tel.: +7-914-731-2777

Citation: Shestakov, N.;

Orlyakovskiy, A.; Perevalova, N.; Titkov, N.; Chebrov, D.; Ohzono, M.; Takahashi, H. Investigation of Ionospheric Response to June 2009 Sarychev Peak Volcano Eruption. Remote Sens. 2021, 13, 638. https:// doi.org/10.3390/rs13040638

Academic Editor: José Fernández

Received: 28 December 2020

Accepted: 8 February 2021

Published: 10 February 2021

Publisher's Note: MDPI stays neutral with regard to jurisdictional claims in published maps and institutional affiliations.

Copyright: (c) 2021 by the authors. Licensee MDPI, Basel, Switzerland. This article is an open access article distributed under the terms and conditions of the Creative Commons Attribution (CC BY) license (https:// creativecommons.org/licenses/by/ $4.0 /)$.

\begin{abstract}
Global Navigation Satellite Systems have been extensively used to investigate the ionosphere response to various natural and man-made phenomena for the last three decades. However, ionospheric reaction to volcano eruptions is still insufficiently studied and understood. In this work we analyzed the ionospheric response to the 11-16 June 2009 VEI class 4 Sarychev Peak volcano eruption by using surrounding Russian and Japanese GPS networks. Prominent covolcanictotal electron content (TEC)ionospheric disturbances (CVIDs) with amplitudes and periods ranged between 0.03-0.15 TECU and 2.5-4.5 min were discovered for the three eruptive events occurred at 18:51 UT, 14 June; at 01:15 and 09:18 UT, 15 June 2009. The estimates of apparent CVIDs velocities vary within 700-1000 m/s in the far-field zone (300-900 km to the southwest from the volcano) and $1300-1800 \mathrm{~m} / \mathrm{s}$ in close proximity toSarychev Peak. The characteristics of the observed TEC variations allow us to attribute them to acoustic mode. The south-southwestward direction is preferred for CVIDs propagation. We concluded that the ionospheric response to a volcano eruption is mainly determined by a ratio between explosion strength and background ionization level. Some evidence of secondary (F2-layer) CVIDs' source eccentric location were obtained.
\end{abstract}

Keywords: volcanic eruption; explosion; GNSS ionosphere sounding; covolcanic ionospheric disturbances

\section{Introduction}

The ionosphere is the layer of charged particles extending within $60-1000 \mathrm{~km}$ above the Earth's surface. Global Navigation Satellite Systems (GNSS) have been extensively used to investigate it for the last three decades. The main advantages of GNSS-sounding compared to other techniques are the high measurement accuracy of total electron content (TEC) relative variations [1] as well as a huge and quickly growing number of globally distributed GNSS-sites. According to numerous studies the ionosphere is sensitive to different man-made and natural phenomena such as rocket launches, explosions [2] (including nuclear tests [3] and asteroid atmospheric blasts [4]), earthquakes [5], tsunamis [6], tropical storms [7], volcano eruptions [8], etc. Contrary to other phenomena the ionosphere response to volcano eruptions is still insufficiently studied and understood mostly due to a limited number of investigated volcanic events and the absence of dense GNSS-arrays in the vicinity of many active volcanoes. 
The June $1991 \mathrm{Mt}$. Pinatubo $\left(15.12^{\circ} \mathrm{N}, 120.33^{\circ} \mathrm{E}\right.$, Philippines) eruption was the first volcanic event in which covolcanic ionospheric disturbances (CVIDs) were explored by using the first generation of GNSS-system-NNSS [9]. The CVIDs generated by the September 2004 Asama volcano $\left(36.24^{\circ} \mathrm{N}, 138.31^{\circ} \mathrm{E}\right.$, Honshu Island, Japan) explosive eruption were detected and analyzed by using Japanese GPS Earth Observation Network (GEONET) [8]. The CVIDs caused by the July 2003 Soufrière Hill volcano $\left(16.43^{\circ} \mathrm{N}, 62.11^{\circ} \mathrm{W}\right.$ Montserrat, Lesser Antilles) and February 2014 Kelud volcano $\left(07.72^{\circ} \mathrm{S}, 112.31^{\circ} \mathrm{E}\right.$ East Java, Indonesia) eruptions were investigated by surrounding GNSS-networks in publications $[10,11]$ and [12].The CVIDs invoked by the April 2015 eruptions of Calbuco volcano (41.33 ${ }^{\circ}$, $72.61^{\circ} \mathrm{W}$ southern Chile) were studied in reference [13]. The volcanic explosivity index (VEI) of the eruptions discussed above vary from 2 to 4 . The amplitudes of the discovered CVIDs range from 0.03 to $0.50 \mathrm{TECU}\left(1 \mathrm{TECU}=10^{16}\right.$ electrons $\left./ \mathrm{m}^{2}\right)$. Their velocity estimates vary from a few hundred to $1200 \mathrm{~m} / \mathrm{s}$ that fits well the gravity and acoustic mode of travelling ionospheric disturbances. Almost all of the described CVIDs arise within 10-20 min after a volcanic explosion and/or ash ejection. They last from a few tenths of minutes up to $2.5 \mathrm{~h}$ after the source event. Most CVIDs were detected at distances rangingfrom 100-200 to $700-800 \mathrm{~km}$ from a volcano. Some arguments for the relationship between the strength of eruption and relative amplitude of the detected CVIDs were provided in [13].

Mt. Pinatubo, Kelud and Asama volcanoes belong to the so-called "Ring of Fire"tectonically active rim of the Pacific Ocean comprising 328 active volcanoes. Its northwestern part (the Commander Islands, the Kamchatka Peninsula and the Kuril Islands) is highly eruptive but it has never been investigated for CVIDs. By this work, we start to fill this gap by studying the ionospheric response to the June 2009 Sarychev Peak volcano $\left(48.10^{\circ} \mathrm{N}\right.$, $153.20^{\circ} \mathrm{E}$, Matua Island, the Kuril Islands Arc) explosive eruption using observation data of Russian and Japanese GNSS-networks.

\section{June 2009 Sarychev Peak Volcano Eruption}

Sarychev Peak stratovolcano (elevation $1446 \mathrm{~m}$ above the sea level) is situated on Matua Island. It belongs to the Kuril Islands Arc and is located as far as $400 \mathrm{~km}$ to the southwest from the Kamchatka Peninsula tip (Russian Federation) and $750 \mathrm{~km}$ to the northeast from Hokkaido Island (Japan) (Figure 1). Strong explosive eruption of Sarychev Peak volcano occurred during 11-16 June 2009 after 33 years of inactivity. Its scale is characterized by the VEI $=4$ (https: / / volcano.si.edu/database/search_eruption_ results.cfm (accessed on 25 December 2020)). The active phase of the eruption consisted of two series of explosions separated by a $13 \mathrm{~h}$ pause [14]. More than 20explosions of different strength and duration resulted in eruptive columns of 3-21 km height. Ash plumes propagated within a few hundred up to $800 \mathrm{~km}$ from the volcano. The eruption chronology was reconstructed primarily based on satellite data including observations from the International Space Station $[14,15]$ and infrasonic measurements provided by the International Monitoring System infrasound network [16,17]. No seismic records of the eruption were obtained by the nearest seismic arrays due to remote location of Matua Island. The main characteristics of the largest eruptive events are summarized in Table 1. Starting epochs of individual explosions were determined by infrasonic data with accuracy of about $5 \mathrm{~min}$ [16]. According to the publication [14] the highest ash plume reached $21 \mathrm{~km}$ altitude above the sea level. It was ejected by the 13 June explosion. However, the work [17] showed that series of the subsequent explosions generated notably larger infrasonic signals (see events 7-10 in Table 1). The a priorianalysis of daily traveltime diagrams formed for each day between 9-19 June 2009 and subsequent inspection of the filtered vertical TECseries (see the next section for the explanations) also showed that the group of explosions occurred at 18:51 UT on 14 June at 01:15 and 09:18 UT on 15 June produced the most intense CVIDs comparing other eruptive events. Thus in the next sections we will focus only on these events. 


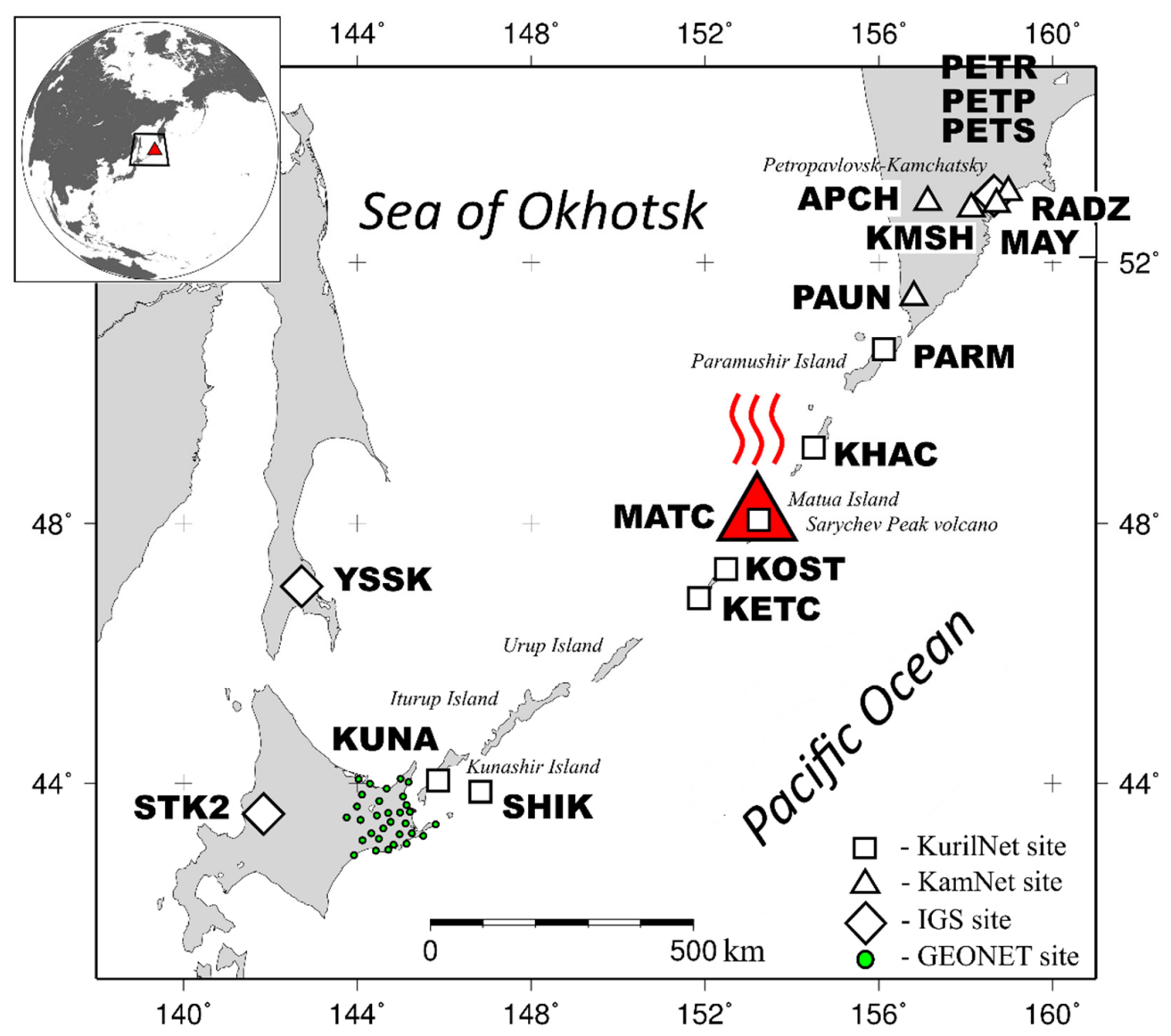

Figure 1. The map of the Kuril Islands Arc and distribution of GPS sites used in this study. The location of Sarychev Peak volcano (Matua Island) is denoted by the red triangle. GPS station names are given in bold. Other notations are shown in the figure.

Table 1. The main characteristics of the largest eruptive events with explosion plume altitudes $\geq 10 \mathrm{~km}$ above the sea level. The start time and duration of each paroxysm are given according to infrasonic observations [17]. The eruptive column height was estimated by satellite data and analysis at SVERT-Sakhalin Volcanic Eruption Response Team (http:/ / www.imgg.ru/ en/svert (accessed on 25 December 2020)). Amplitude of infrasonic signals is given for the nearest global IMS infrasonic network site located in Petropavlovsk-Kamchatsky [17]. The background total electron content(TEC) values were calculated by using IRI2016 online reference ionosphere model (https:/ /ccmc.gsfc.nasa.gov/modelweb/models/iri2016_vitmo.php (accessed on 25 December 2020)).

\begin{tabular}{|c|c|c|c|c|c|c|}
\hline $\begin{array}{c}\text { Event } \\
\text { Number }\end{array}$ & Date & $\begin{array}{c}\text { Event Start Time } \\
\text { UT (Local Time), } \\
\text { HH:MM }\end{array}$ & $\begin{array}{l}\text { Duration, } \\
\text { min }\end{array}$ & $\begin{array}{c}\text { Eruptive } \\
\text { Column Height, } \\
\text { km }\end{array}$ & $\begin{array}{c}\text { Amplitude of } \\
\text { Infrasonic Signals, } \\
\text { Pa }\end{array}$ & $\begin{array}{c}\text { Background } \\
\text { TEC, } \\
\text { TECU }\end{array}$ \\
\hline 1 & 12 June 2009 & 01:38 (12:38) & 117 & 10 & 0.045 & 6.7 \\
\hline 2 & 12 June 2009 & 08:13 (19:13) & 40 & 12 & 0.037 & 8.7 \\
\hline 3 & 13 June 2009 & $01: 57$ (12:57) & 48 & 10 & 0.081 & 6.6 \\
\hline 4 & 13 June 2009 & 04:53 (15:53) & 55 & 10 & 0.108 & 6.7 \\
\hline 5 & 13 June 2009 & $09: 27(20: 27)$ & 34 & 10 & 0.029 & 8.4 \\
\hline 6 & 13 June 2009 & $21: 30(08: 30)$ & 50 & 21 & 0.174 & 7.1 \\
\hline 7 & 14 June 2009 & $18: 51(05: 51)$ & 79 & 16 & 0.235 & 5.4 \\
\hline 8 & 15 June 2009 & $01: 15(12: 15)$ & 39 & 12 & 0.241 & 7.1 \\
\hline 9 & 15 June 2009 & 09:18 (20:18) & 35 & no data & 0.209 & 8.5 \\
\hline 10 & 15 June 2009 & $16: 43(03: 43)$ & 40 & 10 & 0.270 & 4.2 \\
\hline
\end{tabular}

\section{Data and Methods}

Sarychev Peak eruption occurred under the quiet geomagnetic conditions (index $K p \leq 2)$, absence of solar flares and at a low level of the local seismic activity. 
The data of four GNSS-arrays were used to study the ionospheric response to June 2009 Sarychev Peak eruption (Figure 1): IGS-network (International GNSS Service, http: / / www. igs.org/, accessed on 25 December 2020); KurilNet (Kuril GPS Network) deployed under collaboration of a few Russian and USA research institutions [18]; KamNet (Kamchatka GPS Network) maintaining by the Kamchatka Branch of Geophysical Survey of the Russian Academy of Sciences [19] and GEONET (GPS Earth Observation Network) operating by Geospatial Authority of Japan [20]. We used 31 GEONET sites almost evenly distributed through the eastern part of Hokkaido Island. The most distant GPS station was located of about $900 \mathrm{~km}$ whereas the closest site was situated only $5.7 \mathrm{~km}$ from active vent of the volcano. In total, observations of 48 GNSS stations were used in this work. All observation sites were equipped by dual-frequency receivers and tracked only GPS satellites with $30 \mathrm{~s}$ data sampling rate.

The main theoretical aspects of GNSS application to ionosphere sounding are widely known and can be found in a number of publications (see, for example, papers [21-23] and references in them). In this work we adopted a classical approach to TEC data analysis, assuming that all TEC variations occur in a thin F2-layer of maximum ionization [24] (the shell model [1]). The intersection of the line of sight (LOS) between a GPS satellite and a GPS-receiver with this layer is called an ionospheric piercing point (IPP). The IPP sequences were used to analyze spatiotemporal evolution of CVIDs propagation, to calculate distances for the traveltime diagrams and to estimate apparent CVIDs propagation velocities. Thus knowledge of the F2-layer altitude $\left(h_{\max }\right)$ is important for the subsequent TEC analysis.

The value of the F2-layer altitude demonstrates diurnal, seasonal and long-term variations caused by different sources (the Earth rotation, solar activity, different atmospheric and geophysical processes, etc. [25]). The F2-layer height changes within 250-400 km depending on region and geophysical conditions (latitude, observation local time, season, level of geomagnetic activity, etc.). It is problematic to obtain accurate estimate of instantaneous $h_{\text {max }}$ value in a region under study. Usually some mean $h_{\text {max }}$ value is used. The $h_{\text {max }}=300 \mathrm{~km}$ is often adopted (see, for example, papers $[8,26,27]$ ). The better approach is to use data of ionozonde(s) located as close as possible to an observation GNSS-network. In this work we accessed data of the Petropavlovsk-Kamchatsky ionosonde $\left(52.97^{\circ} \mathrm{N}\right.$ 158.24 ${ }^{\circ}$ E, http:/ / www.wdcb.ru/stp/data/ionosphere/46501_petropavlovsk_kamchatsky, accessed on 25 December 2020) located about $630 \mathrm{~km}$ to the northeast from the volcano. O-mode $\left(f=0.834 f_{0} \mathrm{~F} 2\right)$ reflection altitudes (hpF2-height) obtained by the PetropavlovskKamchatsky ionozonde were used for the $h_{\max }$ approximation. The hpF2-height values exhibit notable diurnal changes. However, the ionozonde data do not provide estimates of hpF2-height errors. That is why we fixed $h_{\text {max }}$ value equal to $280 \mathrm{~km}$ basedon linear approximation of daily hpF2-height estimates obtained by the ionosonde during 10-17 June 2009 (see Figure S1).

For each day within 9-19 June 2009 the TEC-SUITE Ver. 0.7.6 utility (http:/ / www. gnss-lab.org/tec-suite.html, accessed on 25 December 2020) was used for reconstructionof slant relative TEC variations from the raw GPS data stored in RINEX format. The slant TEC series were converted to vertical TEC variations by using Klobuchar's mapping function [28]:

$$
V T E C=S T E C \cdot \cos \left[\arcsin \left(\frac{R_{z}}{R_{z}+h_{\max }} \cos \theta_{s}\right)\right],
$$

where VTEC-the vertical TEC value, STEC-the slant TEC value obtained using GNSSobservations, $R_{z}$-the Earth's radius, $h_{\max }$-the altitude of the maximum ionization F2-layer, $\theta_{S}$-the GNSS-satellite elevation angle which can be easily calculated using the broadcast ephemeris of the GNSS-satellite and the GNSS-receiver position. The equation takes into consideration the Earth's sphericity.

For the further analysis we performed a band-pass filtering of the TEC series by applyinga moving average with a time window of $1-5 \mathrm{~min}(3-17 \mathrm{mHz})$. According to a number of our tests this interval provides the most optimal signal to noise ratio. The similar frequency band was used to study CVIDs in other works (e.g., [13]). The brief description 
of the moving average method and its application to TEC data smoothing and filtering is given in File S1.

According to special studies (see, for example, [1,29]) and a great number of researchworks investigating ionospheric response to different natural and man-made phenomena (see, for example, references in publication [22]) errors of differential TEC estimates obtained by using dual-frequency phase GNSS-measurements do not exceed 0.01-0.02 TECU. As can be seen from the following illustrations (see the next section) the typical noise level of our filtered TEC series do not exceed 0.02 TECU.

\section{Results}

\subsection{8:51. UT, 14 June Explosive Event}

The eruption paroxysms accompanied by the intense CVIDs began at 18:51 UT on 14 June (05:51 LT, see Table 1). Ionospheric disturbances were detected by a number of the GPS satellites: G02, 04, 13, 17, 20, 23 and G25.

The first CVIDs were met by the satellite G20 at 19:01:30 UT in $215 \mathrm{~km}$ to the southwest from Sarychev Peak, i.e., 10.5 min after the beginning of the eructation (Figures 2 and 3a). The single train of quasi-periodic oscillations with the maximum amplitude of $0.09 \mathrm{TECU}$, with the period of $3 \mathrm{~min}$ and duration of about $20 \mathrm{~min}$ was detected by the group of satellite G20 IPPs located southward from the volcano (Figure 2). As can be seen from Figures 2 and 3 CVIDs amplitude is quickly attenuating to the southeast from Sarychev Peak. The traveltime diagram (Figure 4) and TEC disturbance maps (Figure 5b-c) also show ionospheric disturbances propagating from the volcano with apparent velocities ranged within $700-1300 \mathrm{~m} / \mathrm{s}$.

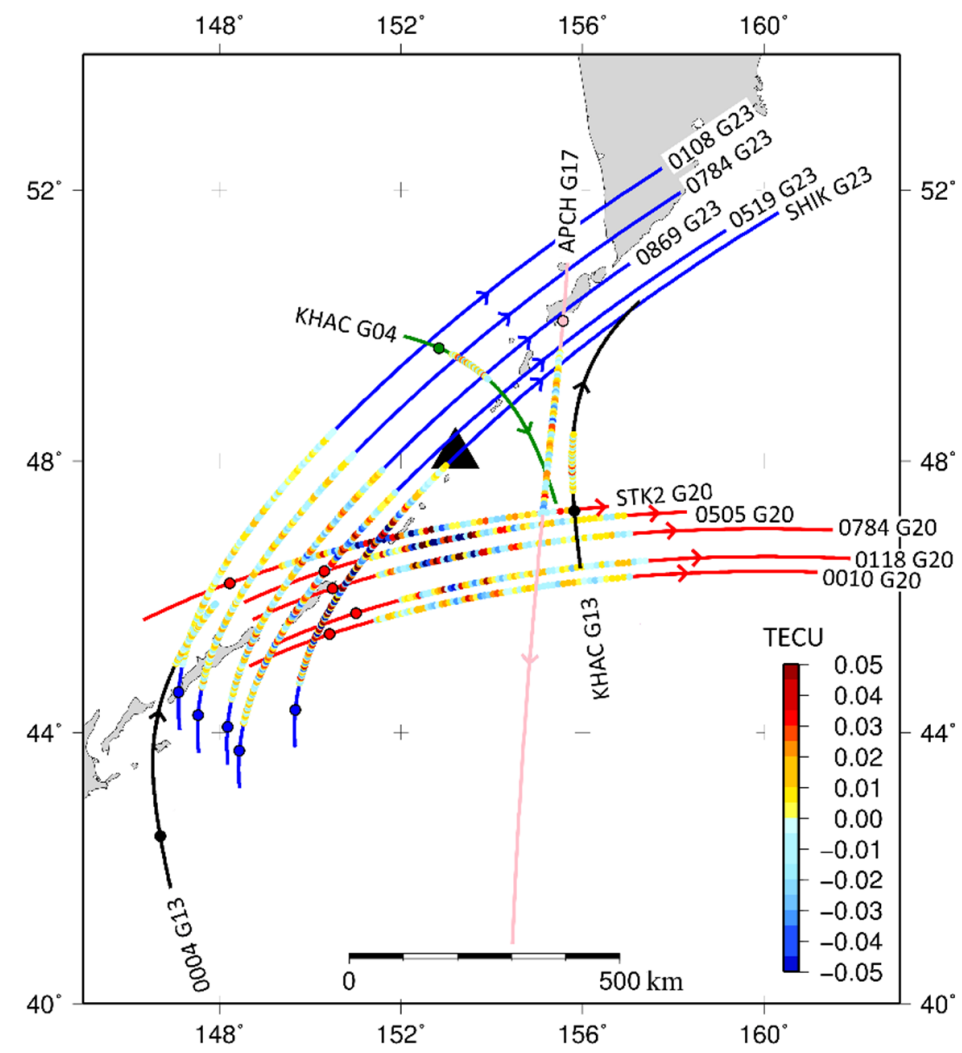

Figure 2. The map of TEC measurements performed during 18:30-21:00 UT on 14 June 2009. Color lines with arrows indicate trajectories of ionospheric piercing points (IPPs). Dots show the IPPs locations at 18:51 UT, i.e., time of the explosion. Observation site name and GPS satellite number are shown near each track. Amplitudes of the most intense TEC disturbances detected by the appropriate site-satellite pairs are plotted by colored dots along each curve. The volcano location is shown by the black triangle. 


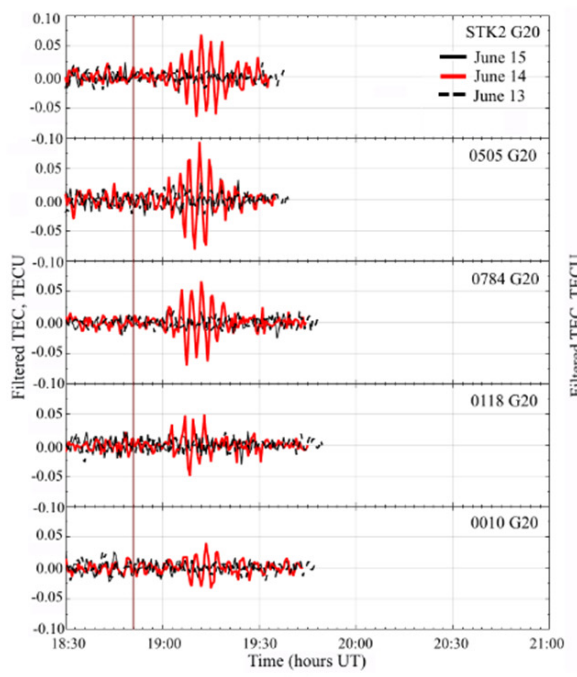

(a)

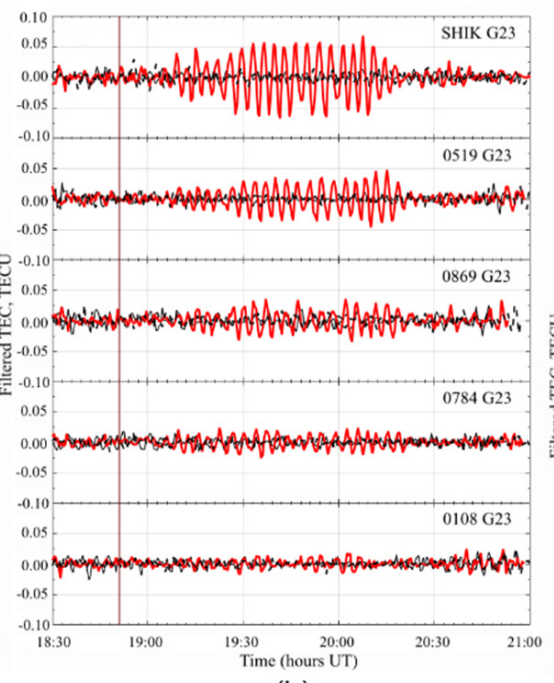

(b)

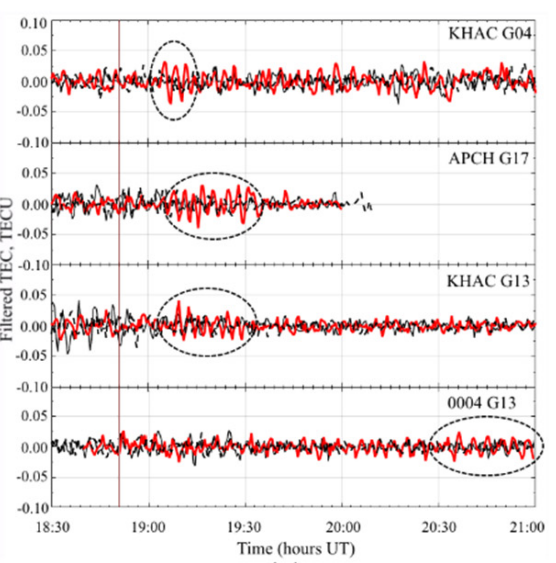

(c)

Figure 3. Examples of covolcanic ionospheric disturbances (CVIDs) triggered by the volcanic explosion occurred at 18:51 UT on 14 June 2009. TEC series for the three consecutive days (13-15 June) are plotted. (a,b) The satellites G20 and G23 filtered vertical TEC series accordingly. (c) Covolcanic filtered TEC variations detected to the north and northeast from the volcano (boxes 1-3 from the top to bottom). The last box shows the example of CVIDs observed after 20:30 UT at $\sim 60 \mathrm{~km}$ to the southwest from Sarychev Peak. Dashed ellipses constraint illegibly discriminated disturbances for clarity. Site names and the GPS satellite numbers are displayed in the upper right corner of each plot. The vertical red solid line indicates the explosion time according to [17] (Table 1, p. 39).

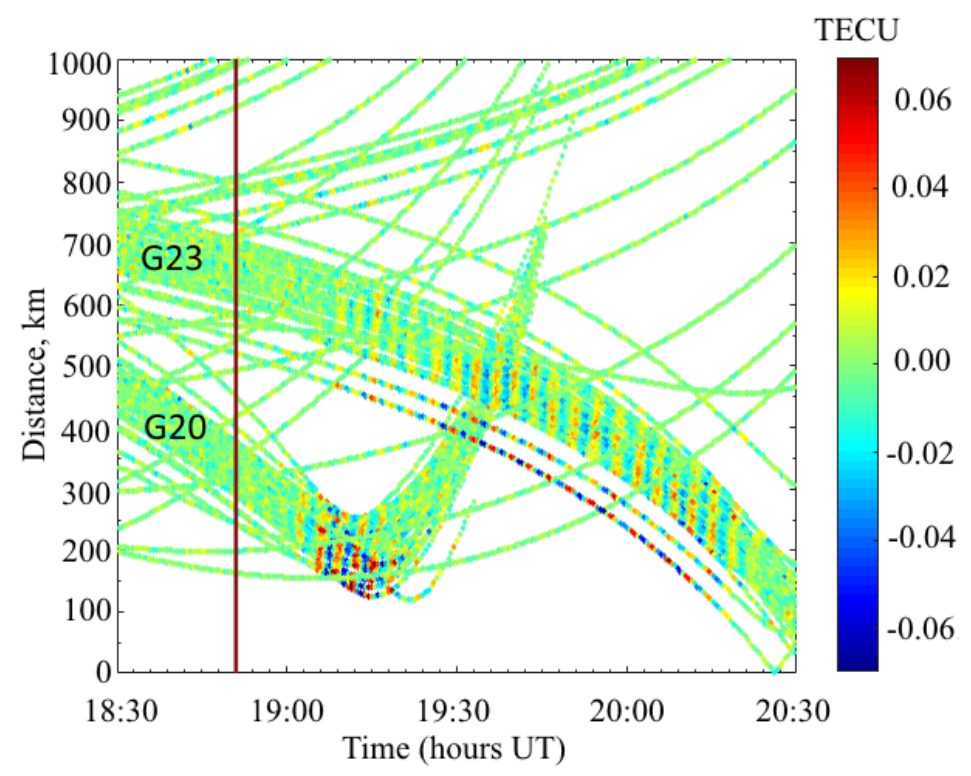

Figure 4. The traveltime diagram plotted by using satellites G20 and G23 within the time span 18:30-20:30 UT on 14 June 2009 shows the most prominent CVIDs. The vertical red solid line indicates the explosion time. Color represents the appropriate TEC amplitude.

Oscillations of much longer duration were revealed by the satellite G23 to the southwest from Sarychev Peak. They lasted of about 74.5 min from 19:05 to 20:19.5 UT (Figures 2 and $3 b)$. The LOS G23-SHIK passed approximately orthogonal to the CVIDs front. It crossed the area right over the volcano and provided the detailed disturbance profile within $480-74 \mathrm{~km}$ out of the volcano. The discovered disturbances are characterized by the oscillation period of $3 \mathrm{~min}$ and maximum amplitude of 0.07 TECU which is slightly less than the amplitude of the CVIDs detected by the satellite G20. The appropriate TEC variations are visible up to $650 \mathrm{~km}$ out of the volcano in the traveltime diagram (Figure 4). 
However, their propagation speed cannot be determined from the diagram. The most probable reason of this problem could be associated with a large space length of the wave packet. TEC disturbance maps also show prominent ionospheric variations at $300-600 \mathrm{~km}$ out of the volcano (Figure 5d,e) which are travelling with velocities of about $700 \mathrm{~m} / \mathrm{s}$.

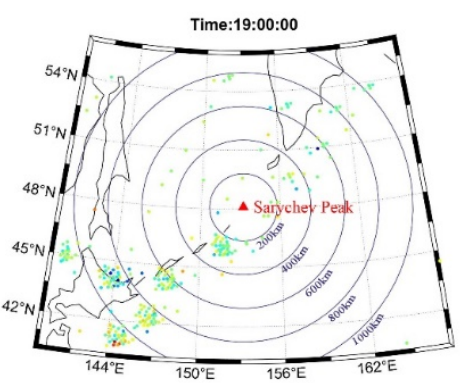

(a)

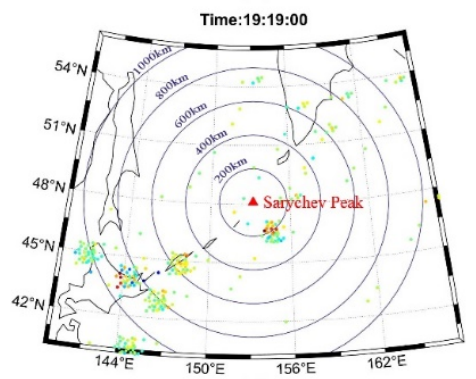

(c)

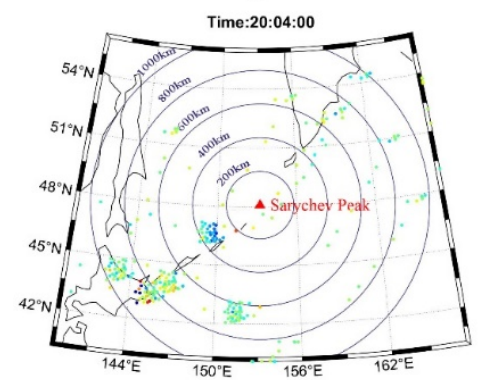

(e)

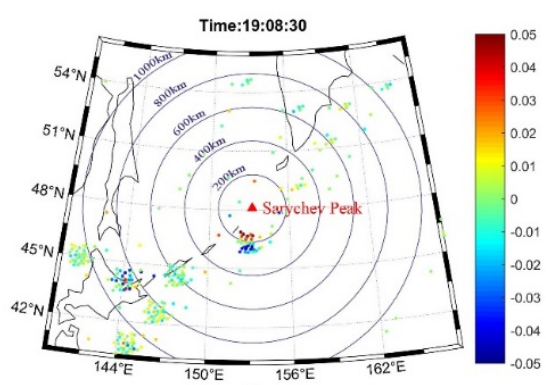

(b)

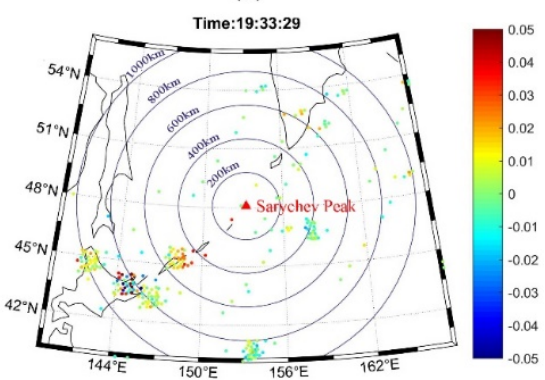

(d)

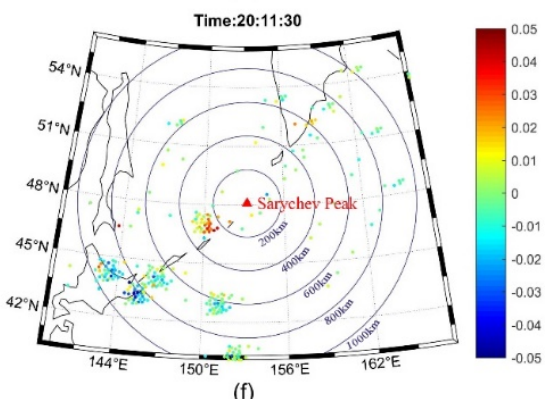

(f)

Figure 5. Examples of spatiotemporal evolution of the observed TEC disturbances generated by the 18:51 UT, 14 June 2009 explosion of Sarychev Peak volcano. (a) The background TEC variations without visible CVIDs. (b,c) The near-field zone covolcanic TEC variation samples. (d-f) The far-field zone covolcanic TEC variation examples. The red triangle shows the location of Sarychev Peak volcano.

The LOSs: G04-KHAC, G13-KHAC, G17-APCH, G17-PAUN, G17-PARM captured CVIDs with amplitudes of 0.02-0.04 TECU within 140-270 km to the north, northeast and east from the volcano (Figures 2 and $3 \mathrm{c}$ ). The amplitudes of these variations are significantly less contrary to disturbances observed in opposite directions. The LOS G04KHAC met CVIDs with period of about $3 \mathrm{~min}$ at 19:02 UT as far as $170 \mathrm{~km}$ to the north from Sarychev Peak. The period of disturbances and their detection distance are close to analogous parameters of the first CVIDs captured by the satellite G20 in opposite direction with respect to the volcano. However, their amplitude is notably less and waveform shape is different (compare Figure 3a,c).

TEC series of four other satellites G02, 04, 13 and 25 also exhibit CVIDs signatures between 20:02-20:45 UT at 600-900 km to the southwest from the volcano. Their amplitudes only barely exceed background TEC variations (the last box in Figure 3c). However, they can be clearly recognized in TEC disturbance maps (see Figure 5f). Their apparent propagation velocities are estimated as large as $\sim 700-800 \mathrm{~m} / \mathrm{s}$.

The general view of the CVIDs spreading can be obtained from Animation S1. 


\subsection{1:15. UT, 15 June Explosive Event}

According to infrasonic data (Table 1 ) the next explosive event occurred $6.4 \mathrm{~h}$ after the previous explosion. Satellites G09, 15, 18, 26-28 showed notable variations in filtered TEC time series obtained within more than $3 \mathrm{~h}$ after the eructation.

The first TEC oscillations most probably correlated with the volcanic activity were detected by LOS G15-KETC at 01:19:30 UT about $51 \mathrm{~km}$ to the south of the volcano, i.e., $4.5 \mathrm{~min}$ after the beginning of the eruption episode (Figures 6 and 7a). The period and maximum amplitude of these variations were equal to $\sim 2.5 \mathrm{~min}$ and 0.06 TECU accordingly. The compact wave packets with maximum amplitude of 0.06-0.09 TECU and period of 2.5-3 min were detected by LOSs G15-MATC and G26-MATC at 75 and $228 \mathrm{~km}$ to the east and northwest from the volcano. They were discovered in 8.5 and $13.5 \mathrm{~min}$ after the first CVIDs detection (Figure 7a). The TEC pulse with amplitude of about $0.05-0.06$ TECU was observed by LOS G09-PARM at 01:27:30 UT $100 \mathrm{~km}$ to the north of Sarychev Peak.

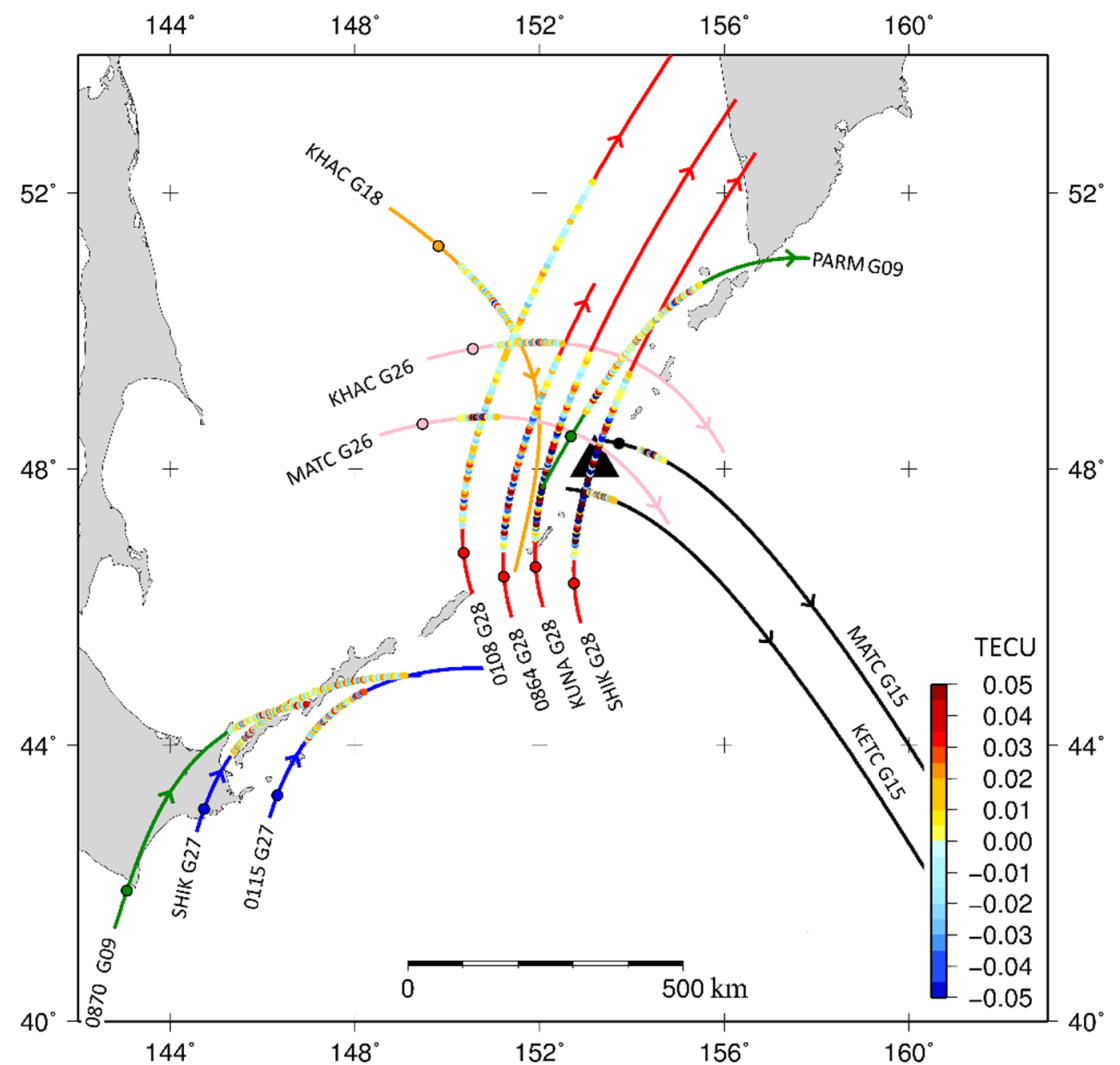

Figure 6. The map of TEC measurements performed during 01:00-04:00 UT on 15 June 2009. Color lines with arrows indicate trajectories of ionospheric piercing points (IPPs). Dots show the IPPs locations at 01:15 UT, i.e., time of the explosion. All other notations are identical to the appropriate ones adopted in Figure 2.

The most prominent and intense CVIDs with maximum amplitude of 0.15 TECU and period of 3 min were recorded by satellite G28 to the southwest and west from Sarychev Peak. The examples of the appropriate waveforms are shown in Figure $7 \mathrm{~b}$. The LOS G28-SHIK passed over the volcano from the southwest to northeast and captured intense TEC variations between 01:27-02:01 UT starting from $146 \mathrm{~km}$ ahead and ending by $105 \mathrm{~km}$ behind the volcano (Figure 6). The duration of the most intense TEC oscillations was equal to $34 \mathrm{~min}$ which is close to the appropriate duration of infrasonic signals triggered by this eruptive event [17]. The maximum TEC perturbation amplitudes were observed at 70-80 km to the southwest from the volcano within 01:38:30-01:40 UT and quickly faded in accordance with northeastward movement of satellite G28. The appropriate ionospheric variations can be clearly seen in the traveltime diagram (Figure 8). 


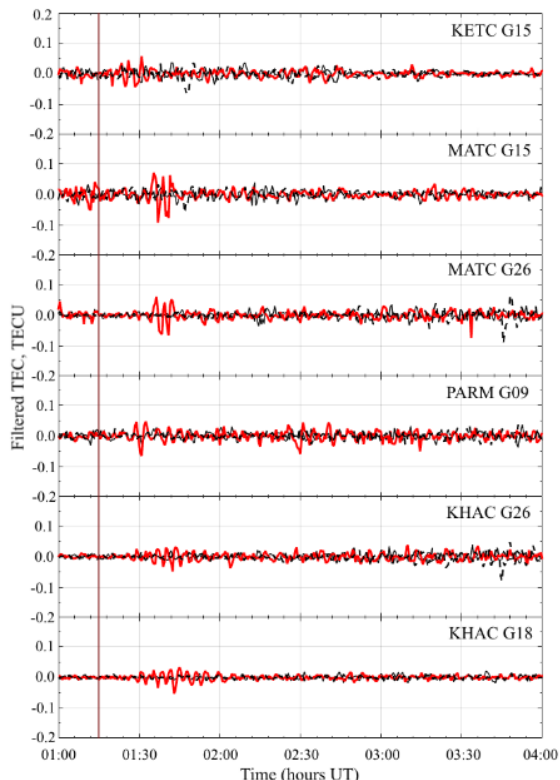

(a)

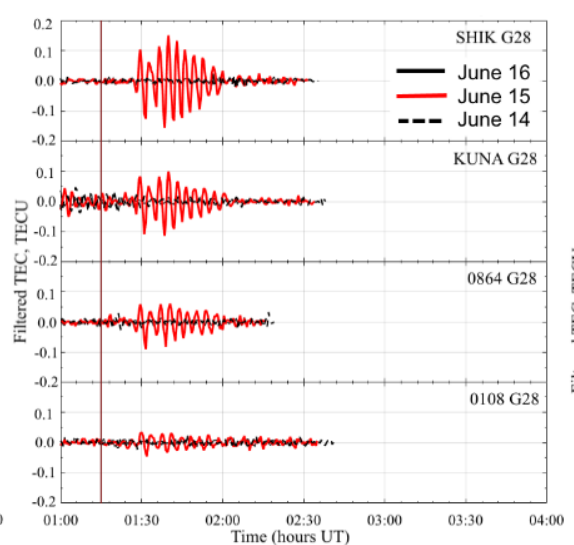

(b)

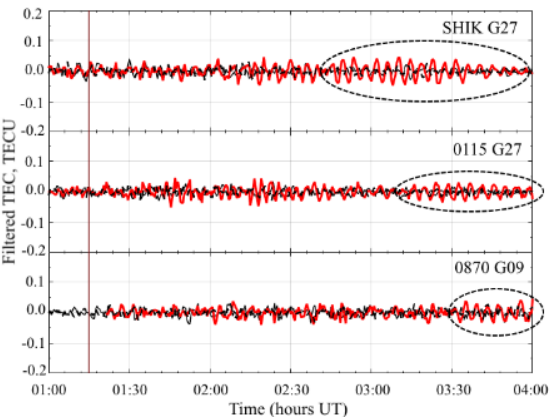

(c)

Figure 7. Examples of covolcanic ionospheric disturbances initiated by the volcanic explosion occurred at 01:15 UT on 15 June 2009. Filtered vertical TEC series are shown for three consecutive days (14-16 June). (a) TEC series exhibiting CVIDs to the north-northeast (MATC-G15, PARM-G09), south (KETC-G15) and northwest (MATC-G26, KHAC-G26, KHAC-G18) from the volcano. (b) TEC series for the satellite G28. (c) The examples of CVIDs observed after 02:30-03:30 UT at $\sim 600-700 \mathrm{~km}$ to the southwest from Sarychev Peak. All other notations are identical to the appropriate ones adopted in Figure 3 .

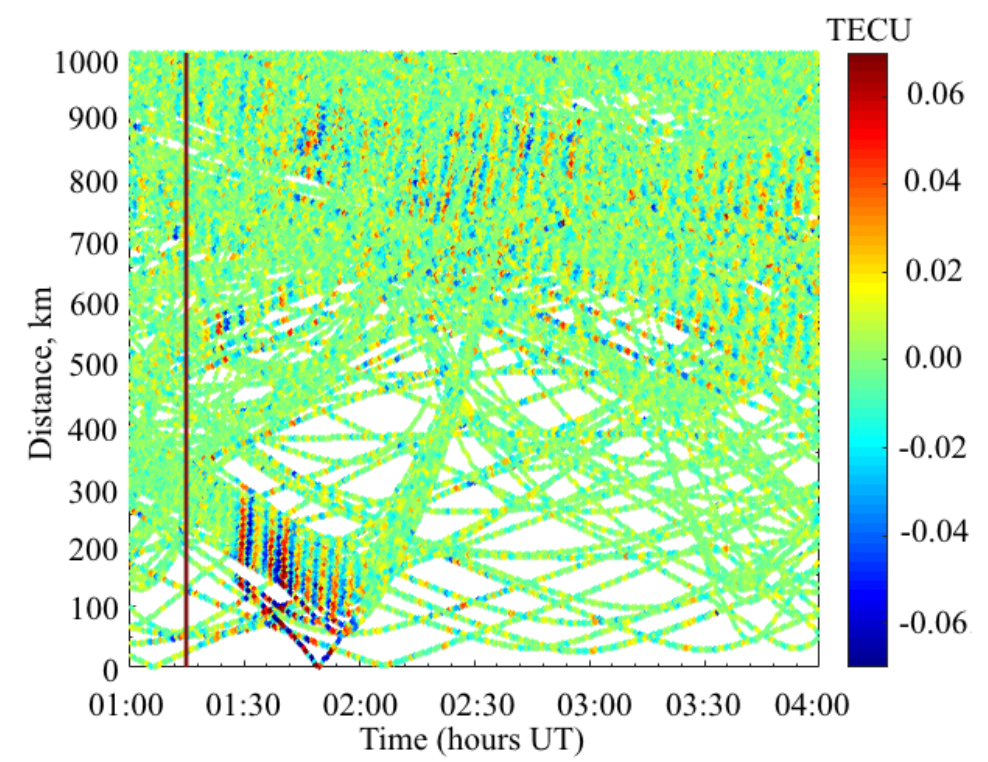

Figure 8. The traveltime diagram plotted by using all visible satellites between 01:00-04:00 UT on 15 June 2009. The vertical red solid line indicates the explosion time. Color represents the appropriate TEC amplitude.

Covolcanic TEC oscillations with longer period of 4-4.5 min and amplitudes of about 0.03-0.04 TECU were detected by the satellites G09 and G27 after 03:00-03:30 UT near Kunashir and Iturup Islands (Figures 6 and 7c).

Analysis of TEC disturbance maps formed for the time interval 01:15-04:30 UT showed that the intense CVIDs were observed between 01:27-02:02 UT to the southwest and west within $\sim 200 \mathrm{~km}$ of the volcano (Figure $9 \mathrm{a}-\mathrm{d}$ ). They propagated with apparent velocities of about $1000 \mathrm{~m} / \mathrm{s}$. Clear CVIDs became visible within 02:18-02:50 UT at 700-900 km 
southwestward from Sarychev Peak (Figure 9e,f). The last portion of relatively long-period CVIDs were recognized between 03:27-04:20 UT about 600-700 km in the same direction away the volcano (Figure $9 \mathrm{~g}, \mathrm{~h}$ ). The appropriate propagation velocities of CVIDs visible in the far-field zone ranged within $800-900 \mathrm{~m} / \mathrm{s}$.

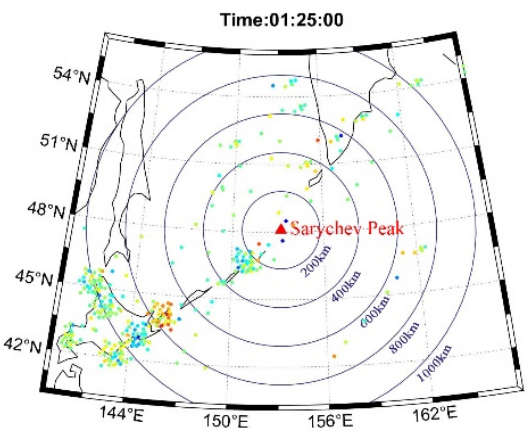

(a)

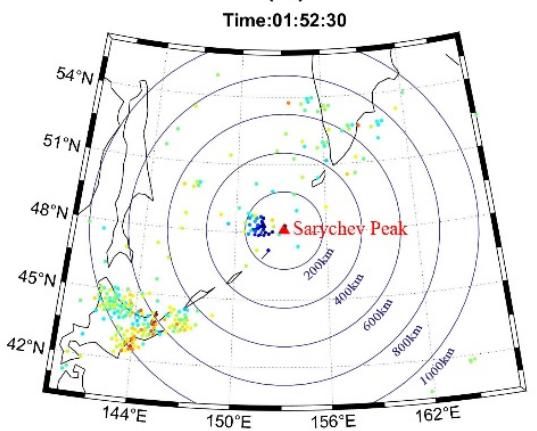

(c)

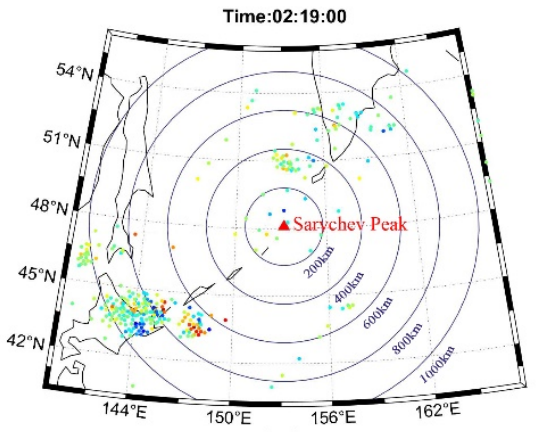

(e)

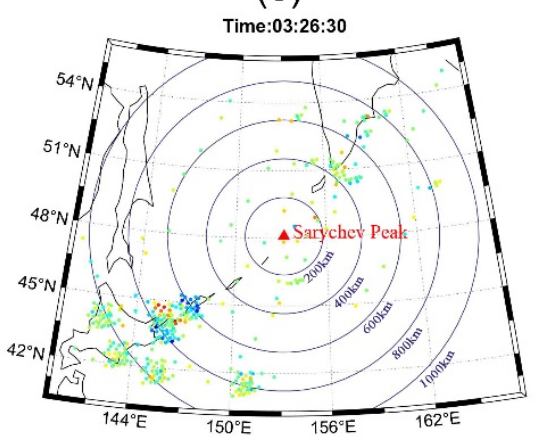

(g)

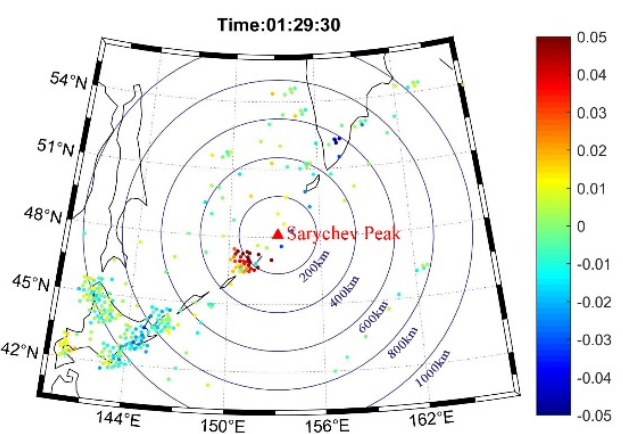

(b)

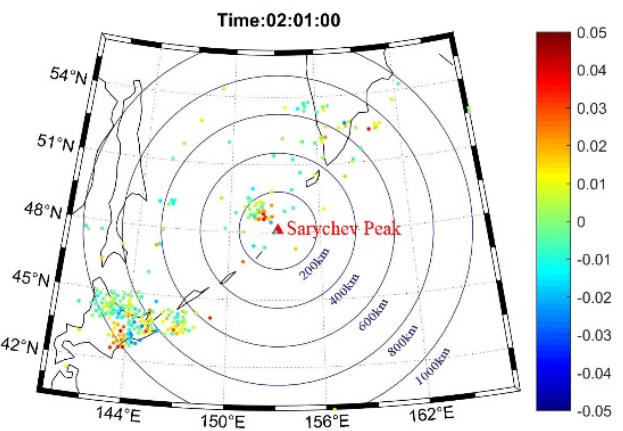

(d)

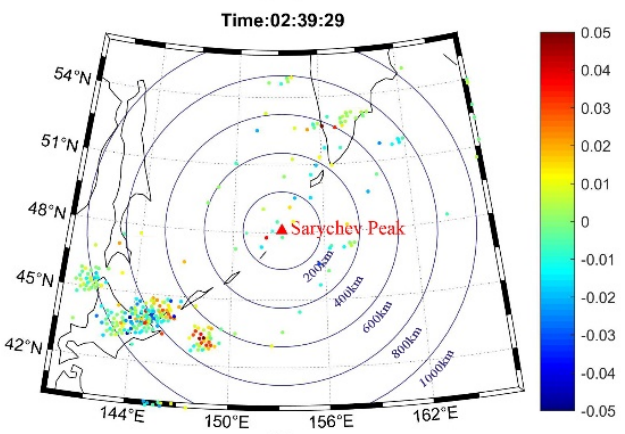

(f)

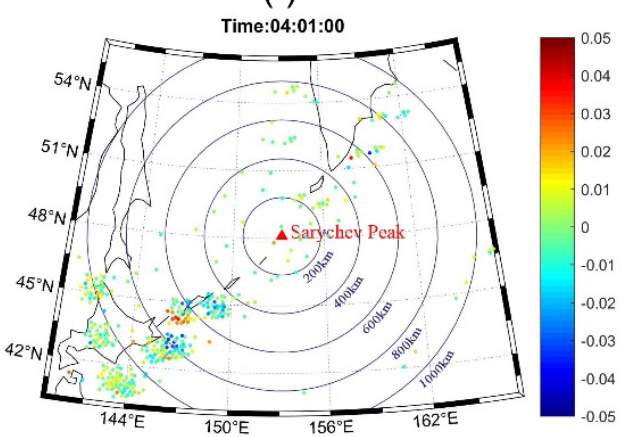

(h)

Figure 9. Examples of spatiotemporal evolution of the observed TEC disturbances invoked by 01:15 UT explosion of Sarychev Peak volcano. (a) The background TEC variations without visible CVIDs. (b-d) The near-field zone covolcanic TEC variation samples. (e-h) The far-field zone covolcanic TEC variation examples. The red triangle shows the location of Sarychev Peak volcano.

The movie illustrating CVIDs propagation is given by Animation S2. 


\subsection{9:18. UT, 15 June Explosive Event}

The last eruptive event initiating significant CVIDs occurred $8 \mathrm{~h}$ after the preceded explosion. Only three satellites G21, 24 and 29 detected TEC variations which could be associated with the volcano activity. The LOSs of the satellites G24 and G29 scanned the region within $300 \mathrm{~km}$ to the southwest, west and northeast from Sarychev Peak (Figure 10). The first CVIDs were detected by the LOS G29-SHIK in $10 \mathrm{~min}$ after the explosion at $\sim 90 \mathrm{~km}$ to the south from the volcano. The LOS G24-SHIK caught the CVIDs at almost the same time and direction (Figure 11a,b). The maximum amplitudes of the recorded disturbances ranged between 0.06-0.09 TECU. The amplitudes of TEC variations observed by the satellite G24 were notably higher than signals detected by satellite G29. Period of the most intense oscillations was equal to $2-2.5$ min whereas the following much lower amplitude variations were characterized by periods of about 3-3.5 min.

The satellite G21 IPPs tracks cover the region to the southwest of the volcano as far as $250-550 \mathrm{~km}$ from it. The chain consisting of two 3.5-4.0 min period wave packets was observed. The oscillations lasted of about 56 and 20 min correspondingly. Their amplitudes were notably lower comparing the CVIDs amplitudes detected by satellites G24 and G29 (Figure 11c). The traveltime diagrams also confirmed excitation of prominent TEC disturbances within 0-600 km from the volcano (Figure 12).

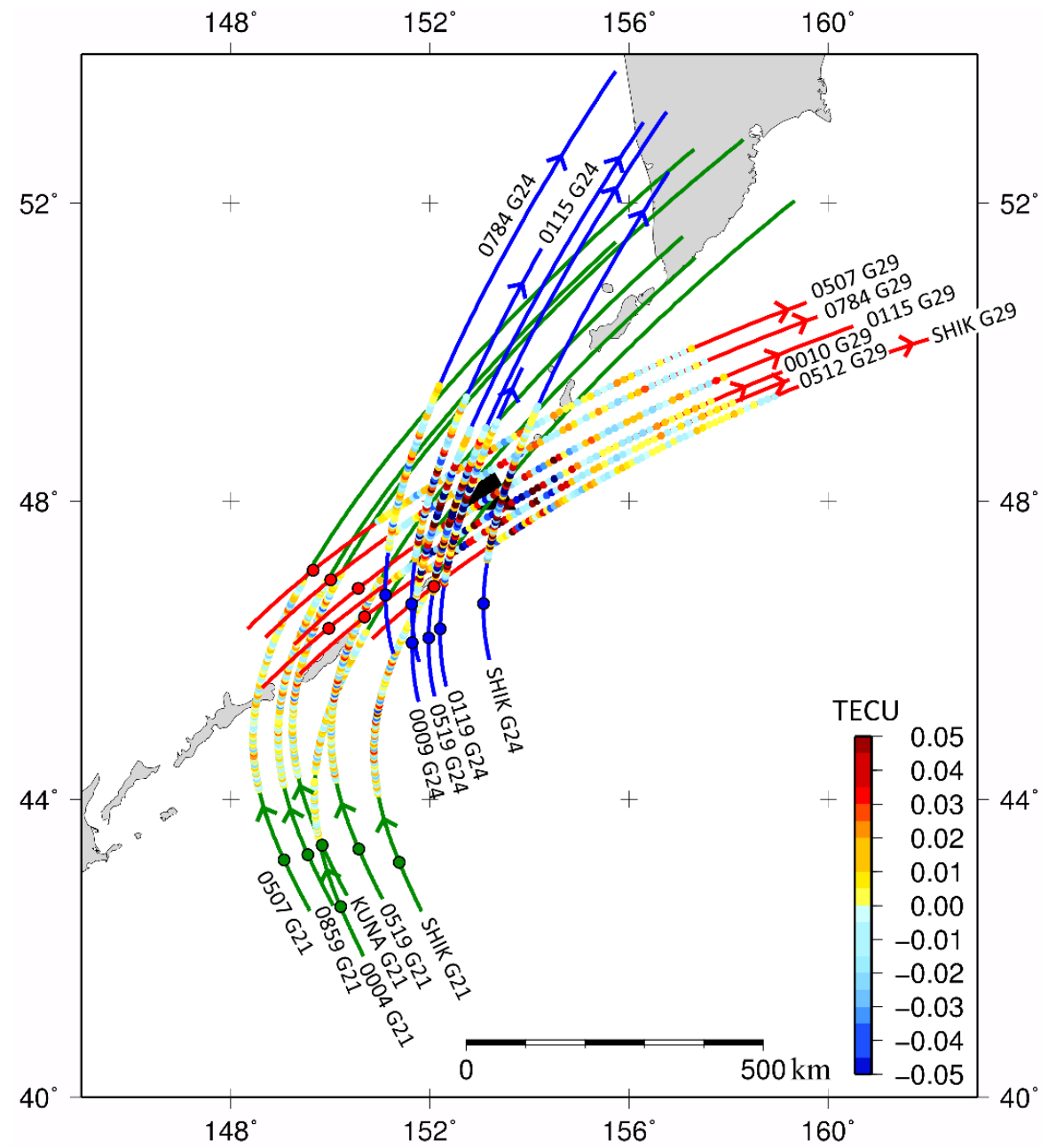

Figure 10. The map of TEC measurements performed during 09:00-13:00 UT on 15 June 2009. Color lines with arrows indicate trajectories of ionospheric piercing points (IPPs). Dots show the IPPs locations at 09:18 UT, i.e., time of the explosion. All other notations are identical to the appropriate ones adopted in Figure 2. 


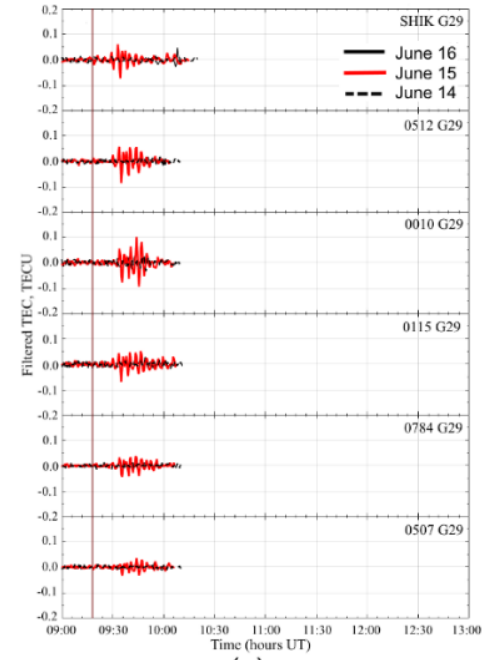

(a)

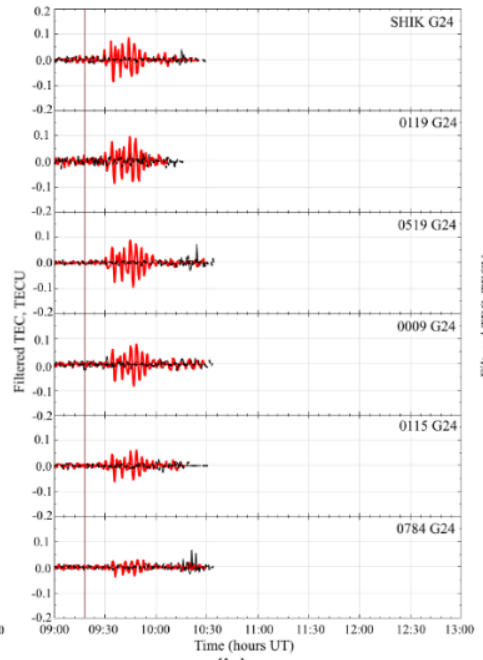

(b)

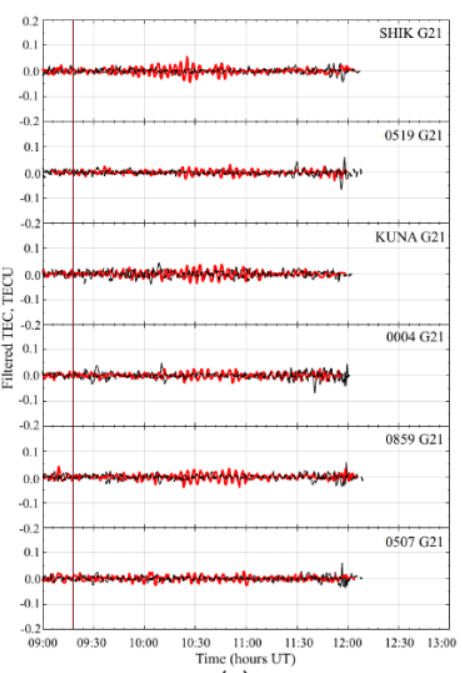

(c)

Figure 11. Examples of covolcanic ionospheric disturbances initiated by the volcanic explosion occurred at 09:18 UT on 15 June 2009. Filtered vertical TEC series are plotted for three consecutive days (14-16 June). (a-c), The satellite G29, G24 and G21 filtered vertical TEC series accordingly. All other notations are identical to the appropriate ones adopted in Figure 3.

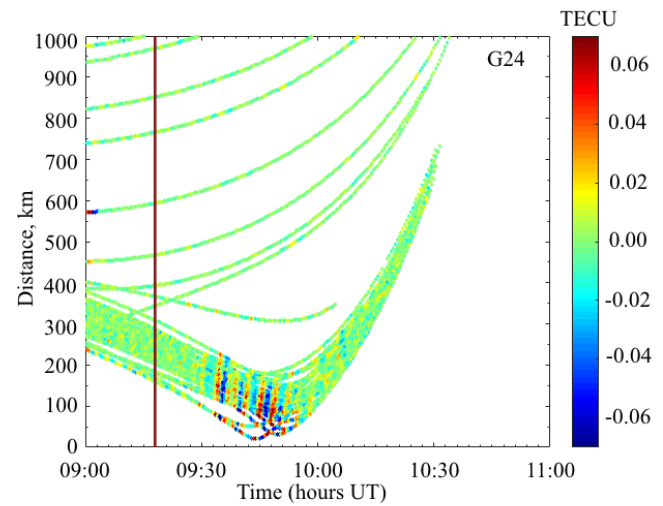

(a)

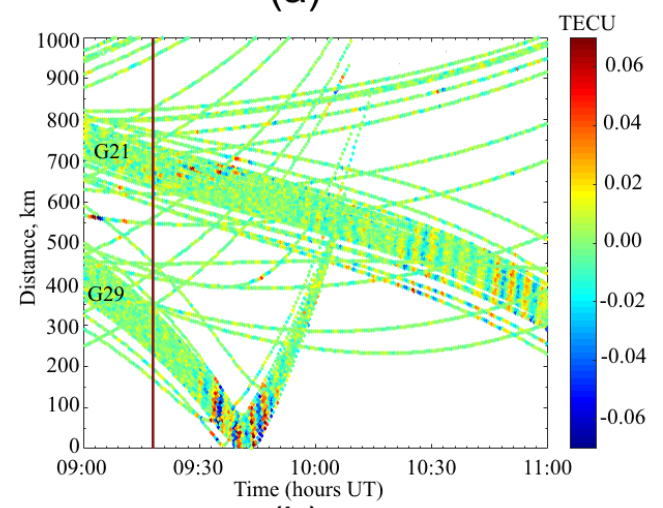

(b)

Figure 12. The traveltime diagram plotted within the time span 09:00-11:00 UT on 15 June 2009 by using (a) satellite G24 and (b) satellites G21, G29. It shows the most prominent CVIDs in the near-field (0-200 km) and far-field zone (300-600 km) with respect to the volcano. The vertical red solid line indicates the explosion time. Color represents the appropriate TEC amplitude.

TEC disturbance maps demonstrate appearance of the first CVIDs to the south and southwest from the volcano at 09:29:30 UT as far as $100 \mathrm{~km}$ from it (Figure 13a). The most intense variationsstarted at 09:33 UT and lasted until 09:59 UT (Figure 13b-d). They 
propagated with apparent velocities of about $1200-1300 \mathrm{~m} / \mathrm{s}$ southwestward and westward from Sarychev Peak.

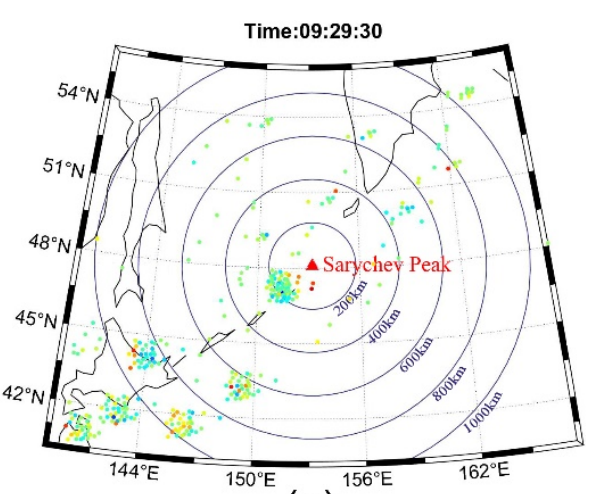

(a)

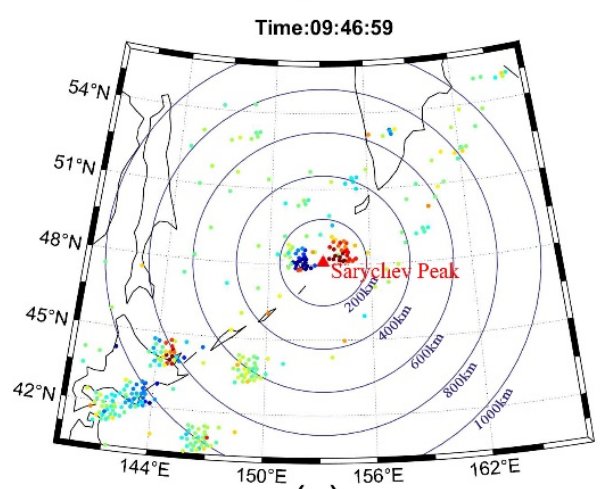

(c)

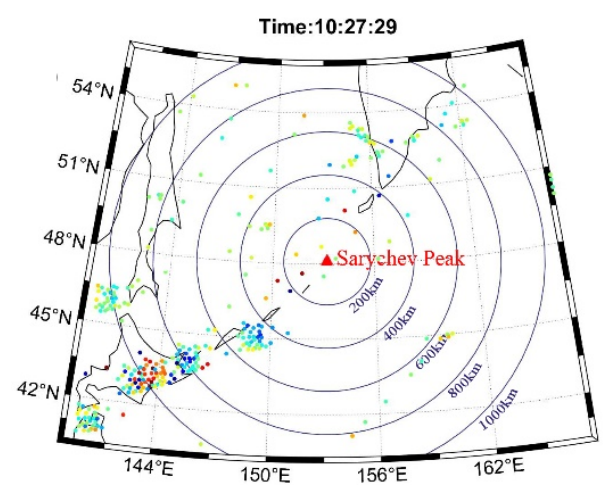

(e)

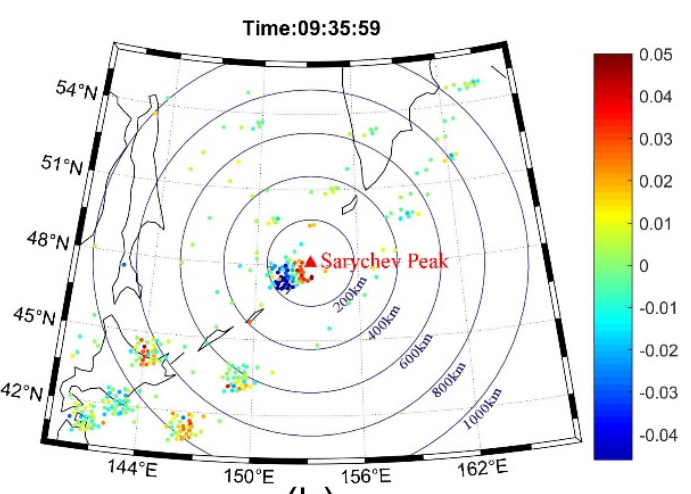

(b)

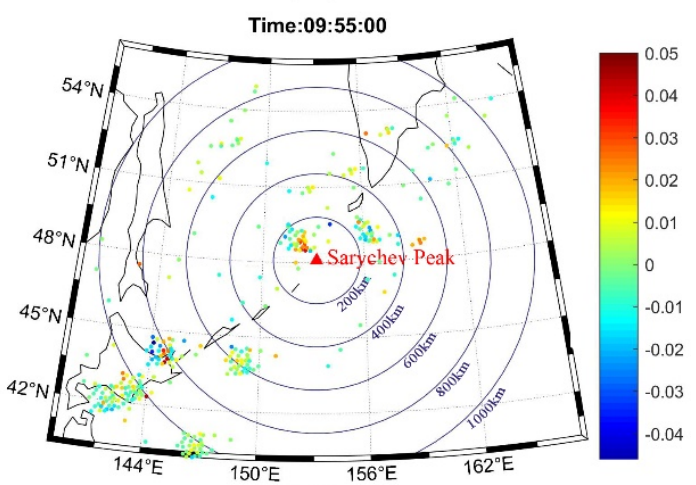

(d)

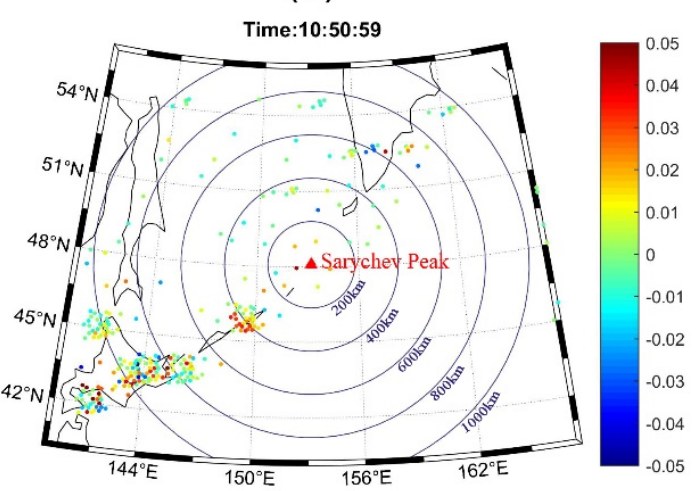

(f)

Figure 13. Examples of spatiotemporal evolution of the observed TEC disturbances initiated by 09:18 UT, 15 June 2009 explosion of Sarychev Peak volcano. (a) The first visible positive phase CVIDs triggered by the volcano explosion. (b-d) The near-field zone covolcanic TEC variation samples. (e,f) The far-field zone covolcanic TEC variation examples. The red triangle shows the location of Sarychev Peak volcano.

Within the time span from 09:40 to 09:52 UT the satellite G29 IPPs passed directly over the volcano from the southwest to northeast. The IPPs of the satellite G24 proceeded to the west of Sarychev Peak as far as 100-200 km from it. The snapshot series (Figure S3) show apparent fronts propagation of CVIDs from the northeast to southwest through the volcano with velocity of about $1800 \mathrm{~m} / \mathrm{s}$. The CVIDs speed quickly faded out to $1200-1300 \mathrm{~m} / \mathrm{s}$ when perturbations moved away from the volcano.

At 10:23 UT the CVIDs reached the group of IPPs located at $400-500 \mathrm{~km}$ to the southwest from Sarychev Peak (Figure 13e,f). Their estimated propagation velocities ranged within 1000-1200 m/s approximately. The disturbances were being observed until 
11:15 UT. It should be noted that the intense background TEC variations were detected around eastern Hokkaido and its vicinities within 9:00-11:30 UT. These variations obviously were not correlated with CVIDs. However, they probably masked covolcanic perturbations which could be detected at $800-900 \mathrm{~km}$ from the volcano as they were observed for the previously considered eruption episodes.

The movie illustrating CVIDs propagation is given by Animation S3.

\section{Discussion}

The 11-16June 2009 eruption of Sarychev Peak volcano provided us a lot of data for CVIDs analysis due to its relatively large scale, long duration, significant number of explosive episodes during the eructation and availability of the GPS networks around the volcano. Analysis of filtered relative vertical TEC variations for the total eruption period showed that a number of paroxysms triggered detectable CVIDs but only three events formed significant perturbations with maximum amplitudes up to 0.09-0.15 TECU. It is notably less comparedwith other class 4 eruptions (see, for example, $[12,13])$. According to publication [13], the most probable explanation of this phenomenon could be related to differences in background ionospheric TEC conditions. Indeed, the calculated background TEC values listed in Table 1 are varying within 4.2-8.7 TECU. It is significantly less compared with the TEC values corresponding to eructation of Kelude and Calbuco volcanoes occurred on 13 February 2014 and 22-23 April 2015 (see Table 2 in [13]). Comparison of strength of explosions and the background ionization level which is given in Table 1 allows us to conclude that their combination determines ionospheric response to a volcanic eruption. For example, the high explosion strength of 16:43 UT, 15 June paroxysm is neutralized by the low background TEC level. However, the 08:13 UT, 12 June and 09:27 UT, 13 June high ionization level was compensated by the small size of the explosions (see the appropriate infrasonic signal amplitudes in Table 1). Other factors such as LOSs configuration with respect to a volcano, the IPPs' remoteness from it also may play an important role in apparent TEC variation formation.

The observed waveforms, oscillation periods $(2.5-4.5 \mathrm{~min})$, estimated propagation velocities (700-1800 m/s) point out at acoustic nature of the detected CVIDs. Spectral analysis of the detected TEC signals leads to the same conclusion (Figure 14). It shows that disturbances of a longer period are observed in the far-field zone compared with the volcano's vicinities.
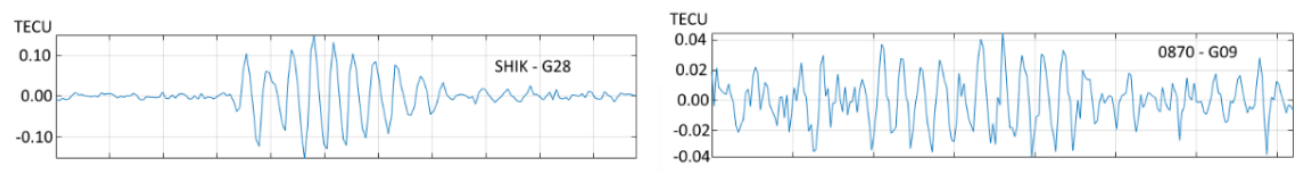

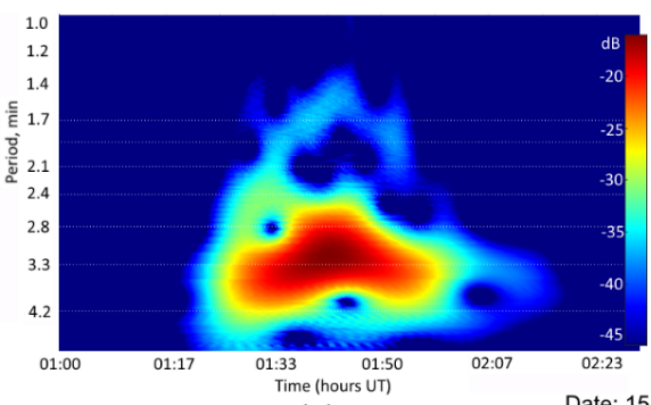

(a)

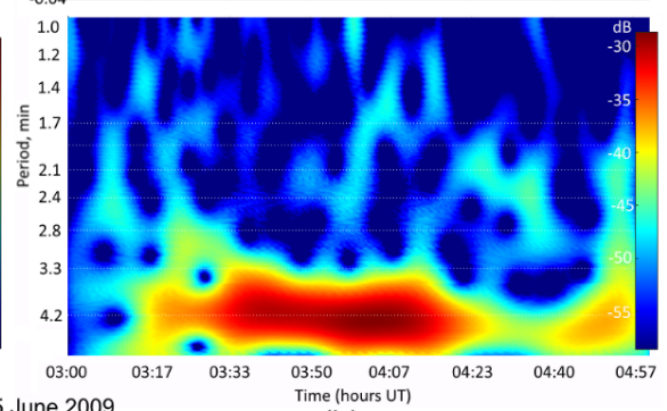

(b)

Figure 14. Examples of filtered vertical TEC series (top plots) and the corresponding spectrograms (bottom plots) (a) for the pair SHIK-G28 (observation site-satellite) showing the compact wave packet with relatively short oscillation period; (b) for the pair 0870-G09 showing the relatively long-duration and long-period covolcanic TEC variations.

Clear azimuthal inhomogeneity of CVIDs propagation was observed for all the considered eruption episodes. In agreement with previous studies [22], the southwestward spread of ionospheric disturbances prevailed among other directions. In this azimuthal 
sector the prominent covolcanic TEC oscillations were registered up to $900 \mathrm{~km}$ from the volcano. However, in northern quadrants we didnot detect CVIDs further than $\sim 200-300 \mathrm{~km}$ from Sarychev Peak. Figures 2, 3, 6, 7, 10 and 11 demonstrate fast decay of disturbance amplitudes to the west from the Kuril Islands Arc. Figure S2 shows an example of such amplitude attenuation. Most probably, this effect could be associated with structure of the magnetic field (Inclination $=60.8^{\circ}$, Declination $=-7.2^{\circ}$ in the volcano vicinities according to EMM2009-2019 model, https:/ /www.ngdc.noaa.gov/geomag/calculators/magcalc. shtml\#igrfwmm, accessed on 25 December 2020) [22]. However, some directivity of CVIDs emission and other possible sources including ionospheric winds also cannot be excluded from consideration.

The observed southwestward propagation of CVIDs in close proximity of the volcano on 15 June during 09:40-09:45 UT raises a question about the location of a source of these perturbations (see Figure S3). Most of the previous studies assumed that the CVIDs source islocated straight over a volcano. However, our observations contradict this assumption and fit better to eccentric position of a virtual ionospheric source which should be placed to the northeast from Sarychev Peak. This assumption may also explain a registration of intense positive phase signals to the northeast from the volcano. It does not match modeling results given in $[22,30]$. These studies stated that only negative TEC signal part can be observed to the north from a source in the northern hemisphere. A possible physical explanation of an eccentric location of the ionospheric CVIDs source may be associated with the upper atmosphere horizontal winds [13]. These flows may notably shift a virtual ionospheric source position at an altitude of the F2-layer. However, further investigations should be undertaken in order to verify this suggestion.

\section{Conclusions}

In this work, we analyzed ionospheric response to the 11-16 June 2009 Sarychev Peak volcano eruption. Three explosive episodes occurred at 18:51 UT on 14 June (Event 1), at 01:15 UT on 15 June (Event 2) and at 09:18 UT (Event 3) were considered. Prominent covolcanic quasi-periodic TEC variations with amplitudes and periods ranged between 0.03-0.15 TECU and 2.5-4.5 min were discovered. For two former volcanic events the notable TEC disturbances were observed more than $3 \mathrm{~h}$ after the explosions. Propagation speed estimates of detected CVIDs varied from 700-1000 m/s in the far-field zone (300-900 km from the volcano) to $1300-1800 \mathrm{~m} / \mathrm{s}$ in close proximity to the volcano. The characteristics of the observed TEC variations obtained allow us to attribute them to the acoustic mode signals.

Duration of the most intense TEC oscillations triggered by the eruptive events seems to be correlated with the duration of infrasonic signals (see Table 1): Event 1-76 min, Event 2-34 min, Event 3-26 min. TEC signals amplitude does not directly depend on explosion strength and eruptive column height. It is constrained by a complex of factors including background ionization level, wave front-LOS relative configuration and other reasons.

The southwestward propagation of the CVIDs prevails among other directions. In this direction the prominent covolcanic TEC disturbances could be detected up to $900 \mathrm{~km}$ away from Sarychev Peak whereas in north azimuth quadrants they were discriminated only within $300 \mathrm{~km}$.

In this study, we obtained some evidence of possible eccentric position of ionospheric CVIDs source (secondary F2-layer source). The limited observation data amount remains an open question for future investigations.

Quick ionospheric response to strong volcanic explosions (in this study: Event 1$10.5 \mathrm{~min}$, Event $2-4.5 \mathrm{~min}$, Event $3-10 \mathrm{~min}$ ) opens promising prospects for development of volcanic eruption early warning systems based on real-time TEC data provided by GNSS networks. The equatorward CVIDs propagation in northern hemisphere, configuration of GNSS orbital segments should be taken into account to design optimal LOS and IPPs coverage around a monitored volcano. Additional investigations should be undertaken in this direction in the near future. 
Supplementary Materials: The following are available online at https:/ /www.mdpi.com/2072-429 $2 / 13 / 4 / 638 / s 1$, Figure S1: O-mode $\left(f=0.834 f_{0} \mathrm{~F} 2\right)$ reflection altitudes obtained by the PetropavlovskKamchatsky ionozonde. The linear regression curve is given by the dashed line. Figure S2: The TEC disturbance map plotted for the epoch 09:34:00 UT on 15 June 2009 and showingthe positive phase CVIDs with the amplitudes decreasing in the west-northwest direction. Figure S3: Spatiotemporal evolution of the CVIDs registered between 09:40:00-09:49:29 UT on 15 June 2009 in the close proximity to Sarychev Peak volcano. Animation S1: Propagation of the covolcanic ionospheric disturbances between 18:30-22:00 UT triggered by Sarychev Peak volcano paroxysm occurred at 18:51 UT on 14 June 2009. Animation S2: Propagation of the covolcanic ionospheric disturbances between 00:4504:15 UT triggered by Sarychev Peak volcano paroxysm occurred at 01:15 UT on 15 June 2009. Animation S3: Propagation of the covolcanic ionospheric disturbances between 08:48-13:18 UT triggered by Sarychev Peak volcano paroxysm occurred at 09:18 UT on 15 June 2009.

Author Contributions: Conceptualization, N.S., N.P.; methodology, N.S. and N.P.; software, A.O.; validation, N.S., A.O., N.P. and H.T.; data curation, N.T., D.C. and M.O.; writing, N.S. and N.P. All authors have read and agreed to the published version of the manuscript.

Funding: This research was funded by RFBR grant number 20-05-00509a and grants of JSPS KAKENHI numbers 19H01984, 20KK0073, 25257204.

Institutional Review Board Statement: Not applicable.

Informed Consent Statement: Not applicable.

Data Availability Statement: TEC data and additional processing results are available by a request. Please, contact to Shestakov Nikolay (shestakov.nv@dvfu.ru).

Acknowledgments: The authors are grateful to Geospatial Information Authority of Japan for GEONET GPS data. We are thankful to UNAVCO for KurilNet and Kamchatka Branch of Geophysical Survey, RAS for KamNetGPS datawhich were obtained with large-scale research facilities «Seismic infrasound array for monitoring Arctic cryolitozone and continuous seismic monitoring of the Russian Federation, neighboring territories and the world» (https://ckp-rf.ru/usu/507436/ (accessed on 25 December 2020)). IGS network data were used in this study. GMT software and MATLAB Ver. R2015b were partially used to produce figures.

Conflicts of Interest: The authors declare no conflict of interest.

\section{References}

1. Hofmann-Wellenhof, B.; Lichtenegger, H.; Wasle, E. GNSS-Global Navigation Satellite Systems, 1st ed.; Springer: Vienna, Austria, 2008; 518p.

2. Calais, E.; Minster, J.B.; Hofton, M.; Hedlin, M. Ionospheric signature of surface mine blasts from Global Positioning System measurements. Geophys. J. Int. 1998, 132, 191-202. [CrossRef]

3. Yang, Y.-M.; Garrison, J.L.; Lee, S.-C. Ionospheric disturbances observed coincident with the 2006 and 2009 North Korean underground nuclear tests. Geophys. Res. Lett. 2012, 39, L02103. [CrossRef]

4. Perevalova, N.P.; Shestakov, N.V.; Voeykov, S.V.; Takahashi, H.; Guojie, M. Ionospheric disturbances in the vicinity of the Chelyabinsk meteoroid explosive disruption as inferred from dense GPS observations. Geophys. Res. Lett. 2015, 42, 6535-6543. [CrossRef]

5. Afraimovich, E.; Feng, D.; Kiryushkin, V.; Astafyeva, E. Near-field TEC response to the main shock of the 2008 Wenchuan earthquake. EarthPlanets Space 2010, 62, 899-904. [CrossRef]

6. Galvan, D.A.; Komjathy, A.; Hickey, M.P.; Mannucci, A.J. The 2009 Samoa and 2010 Chile tsunamis as observed in the ionosphere using GPS total electron content. J. Geophys. Res. 2011, 116, A06318. [CrossRef]

7. Polyakova, A.S.; Perevalova, N.P. Investigation into impact of tropical cyclones on the ionosphere using GPS sounding and NCEP/NCAR Reanalysis data. Adv. Space Res. 2011, 48, 1196-1210. [CrossRef]

8. Heki, K. Explosion energy of the 2004 eruption of the Asama Volcano, central Japan, inferred from ionospheric disturbances. Geophys. Res. Lett. 2006, 33, L14303. [CrossRef]

9. Cheng, K.; Huang, Y.N. Ionospheric disturbances observed during the period of Mount Pinatubo eruptions in June 1991. J. Geophys. Res. 1992, 97, 16995-17004. [CrossRef]

10. Dautermann, T.; Calais, E.; Lognonné, P.; Mattioli, G.S. Lithosphere-atmosphere-ionosphere coupling after the 2003 explosive eruption of the Soufriere Hills Volcano, Montserrat. Geophys. J. Int. 2009, 179, 1537-1546. [CrossRef]

11. Dautermann, T.; Calais, E.; Mattioli, G.S. Global Positioning System detection and energy estimation of the ionospheric wave caused by the 13 July 2003 explosion of the Soufrière Hills Volcano, Montserrat. J. Geophys. Res. 2009, 114, B02202. [CrossRef] 
12. Nakashima, Y.; Heki, K.; Takeo, A.; Cahyadi, M.N.; Aditiya, A.; Yoshizawa, K. Atmospheric resonant oscillations by the 2014 eruption of the Kelud volcano, Indonesia, observed with the ionospheric total electron contents and seismic signals. Earth Planet. Sci. Lett. 2016, 434, 112-116. [CrossRef]

13. Shults, K.; Astafyeva, E.; Adourian, S. Ionospheric detection and localization of volcano eruptions on the example of the April 2015 Calbuco events. J. Geophys. Res. Space Phys. 2016, 121, 10303-10315. [CrossRef]

14. Levin, B.W.; Rybin, A.V.; Vasilenko, N.F.; Prytkov, A.S.; Chibisova, M.V.; Kogan, M.G.; Steblov, G.M.; Frolov, D.I. Monitoring of the eruption of the Sarychev Peak Volcano in Matua Island in 2009 (central Kurile islands). Dokl. Earth Sci. 2010, 435, 1507-1510. [CrossRef]

15. Sakhalin Volcanic Eruptions Response Team (SVERT). Widespread Plumes from Large 11-16 June 2009 Eruption. Bulletin of the Global Volcanism Network, Monthly Report 06/2009, 34:06, Smithsonian Global Volcanism Program. 2009. Available online: https:/ /volcano.si.edu/volcano.cfm?vn=290240\&vtab=Bulletin (accessed on 25 December 2020).

16. Christie, D.R.; Campus, P. The IMS infrasound network: Design and establishment of infrasound stations. In Infrasound Monitoring for Atmospheric Studies; Le Pichon, A., Blanc, E., Hauchecorne, A., Eds.; Springer: Dordrecht, The Netherlands, 2010; pp. 29-75.

17. Matoza, R.S.; Le Pichon, A.; Vergoz, J.; Herry, P.; Lalande, J.-M.; Lee, H.-I.; Che, I.-Y.; Rybin, A. Infrasonic observations of the June 2009 Sarychev Peak eruption, Kuril Islands: Implications for infrasonic monitoring of remote explosive volcanism. J. Volcanol. Geotherm. Res. 2011, 200, 35-48. [CrossRef]

18. Kogan, M.G.; Vasilenko, N.F.; Frolov, D.I.; Freymueller, J.T.; Steblov, G.M.; Prytkov, A.S.; Ekström, G. Rapid postseismic relaxation after the great 2006-2007 Kuril earthquakes from GPS observations in 2007-2011. J. Geophys. Res. Solid Earth 2013, 118, 3691-3706. [CrossRef]

19. Levin, V.E.; Bakhtiarov, V.F.; Titkov, N.N.; Serovetnikov, S.S.; Magus'kin, M.A.; Lander, A.V. Contemporary crustal movements (CCMs) in Kamchatka. Izv. Phys. Solid Earth 2014, 50, 732-751. [CrossRef]

20. Tsuji, H.; Hatanaka, Y.; Hiyama, Y.; Yamaguchi, K.; Furuya, T.; Kawamoto, S.; Fukuzaki, Y. Twenty-Year Successful Operation of GEONET. Bull. Geospat. Inf. Auth. Jpn. 2017, 65, 19-44.

21. Afraimovich, E.L.; Palamartchouk, K.S.; Perevalova, N.P. GPS radio interferometry of travelling ionospheric disturbances. J. Atmos. Solar-Terr. Phys. 1998, 60, 1205-1223. [CrossRef]

22. Astafyeva, E. Ionospheric detection of natural hazards. Rev. Geophys. 2019, 57, 1265-1288. [CrossRef]

23. Afraimovich, E.L.; Astafyeva, E.I.; Demyanov, V.V.; Edemskiy, I.K.; Gavrilyuk, N.S.; Ishin, A.B.; Kosogorov, E.A.; Leonovich, L.A.; Lesyuta, O.S.; Palamartchouk, K.S.; et al. A review ofGPS/GLONASS studies of the ionospheric response to natural and anthropogenic processes and phenomena. J. Space Weather. Space Clim. 2013, 3, A27. [CrossRef]

24. Calais, E.; Minster, J.B. GPS detection of ionospheric perturbations following the January 17, 1994, Northridge earthquake. Geophys. Res. Lett. 1995, 22, 1045-1048. [CrossRef]

25. Hargreaves, J.K. The Solar-Terrestrial Environment; Cambridge University Press: Cambridge, UK, 1992; 420p.

26. Cahyadi, M.N.; Rahayu, R.W.; Heki, K.; Nakashima, Y. Harmonic ionospheric oscillation by the 2010 eruption of the Merapi volcano, Indonesia, and the relevance of its amplitude to the mass eruption rate. J. Volcanol. Geotherm. Res. 2020, 405, 107047-107055. [CrossRef]

27. Astafyeva, E.; Rolland, L.M.; Sladen, A. Strike-slip earthquakes can also be detected in the ionosphere. Earth Planet. Sci. Lett. 2014, 405, 180-193. [CrossRef]

28. Klobuchar, J.A. Ionospheric time delay algorithm for single-frequency GPS-users. IEEE Trans. Aerosp. Electron. Syst. 1986, 23, 325-331. [CrossRef]

29. Coster, A.; Williams, J.; Weatherwax, A.; Rideout, W.; Herne, D. Accuracy of GPS total electron content: GPS receiver bias temperature dependence. Radio Sci. 2013, 48, 190-196. [CrossRef]

30. Rolland, L.M.; Vergnolle, M.; Nocquet, J.-M.; Sladen, A.; Dessa, J.-X.; Tavakoli, F.; Nankali, H.R.; Cappa, F. Discriminating the tectonic and nontectonic contributions in the ionospheric signature of the 2011, Mw7.1, dip-slip Van earthquake, Eastern Turkey. Geophys. Res. Lett. 2013, 40, 2518-2522. [CrossRef] 